\title{
Anti-Oxidative, Anti-Hyperglycemic and Lipid-Lowering Effects of Aqueous Extracts of Ocimum sanctum L. Leaves in Diabetic Rats
}

\author{
Thamolwan Suanarunsawat ${ }^{1}$, Watcharaporn Devakul Na Ayutthaya ${ }^{2}$, \\ Suwan Thirawarapan ${ }^{3}$, Somlak Poungshompoo ${ }^{4}$ \\ ${ }^{1}$ Physiology Unit, Department of Medical Sciences, Faculty of Science, Rangsit University, Pathumtani, \\ Thailand \\ ${ }^{2}$ Pharmacology and Toxicology Unit, Department of Medical Sciences, Faculty of Science, Rangsit University, \\ Pathumtani, Thailand \\ ${ }^{3}$ Department of Physiology, Faculty of Pharmacy, Mahidol University, Bangkok, Thailand \\ ${ }^{4}$ Department of Pathology, Faculty of Veterinary Science, Chulalongkorn University, Bangkok, Thailand \\ Email: tmw706@gmail.com
}

Received 10 February 2014; revised 10 March 2014; accepted 17 March 2014

Copyright (C) 2014 by authors and Scientific Research Publishing Inc.

This work is licensed under the Creative Commons Attribution International License (CC BY).

http://creativecommons.org/licenses/by/4.0/

\section{(c) (i) Open Access}

\section{Abstract}

The present study was conducted to investigate the effect of aqueous extracts of Ocimum sanctum L. leaves on blood glucose, serum lipid profile and anti-oxidative activity to protect various risk organs in DM rats. Ocimum sanctum L. leaves were extracted using water, then the total phenolic content was determined. Three groups of male Wistar rats were used including normal control rats, DM rats and DM rats daily fed with aqueous extracts of Ocimum sanctum L. leaves (AQOS) for three weeks. DM rats were induced by intraperitoneal injection of streptozotocin $(65 \mathrm{mg} / \mathrm{kgbw})$. The results show that three weeks of diabetic induction increased blood glucose, serum lipid profile and serum levels of AST, ALT, ALP, LDH, CK-MB, creatinine and BUN. AQOS significantly decreased blood glucose, serum lipid profile and serum levels of AST, ALT, ALP, LDH, CK-MB, creatinine and BUN. The low level of serum insulin was also raised by AQOS. AQOS suppressed high TBARS level and raised the activities of antioxidant enzymes in the liver, kidney and cardiac tissues. Histopathological results show that AQOS preserved the liver, kidney and myocardial tissues. It can be concluded that AQOS had anti-hyperglycemic, anti-hyperlipidemic, and free radical scavenging effects providing organ protection from diabetes. The phenolic compounds contained in AQOS might be responsible for these activities. 


\section{Keywords}

\section{Ocimum sanctum L. Leaves; Diabetic Rats; Antioxidant Enzymes; Phenolic Compound}

\section{Introduction}

Diabetes mellitus (DM) is a chronic metabolic disease characterized by high blood glucose levels, and often associated with dyslipdemia and oxidative stress which can affect nearly every organ systems in the body. The primary cause of DM is either insulin deficiency or insulin dysfunction which impairs metabolism of carbohydrates, lipids and proteins, leading to long term health complications such as diabetic nephropathy, neuropathy, hypertension, and cardiovascular disease (CVD) [1] [2]. DM is rapidly becoming a global health issue that may overtake cancer during the next two decades. Moreover, its morbidity and mortality rate is continuously increasing. It has been reported that the number of people who have diabetes will increase to 360 - 380 million in 2025-2030 [3]. To treat DM, hypoglycemic drugs, especially insulin, are recommended. However their undesirable side effects, cost, safety on long-term use, and simplicity of administration have been an issue [4]. These factors do not fulfill conditions for patients' compliance. Therefore, physicians are searching for medicinal plants capable of curing diabetes. There are several kinds of medicinal plants that exhibit antioxidant and antihyperglycemic activities. Among them, Ocimum sanctum L. (OS) is very promising as it is routinely used as cooking vegetable, and also has been recommended for the treatment of several diseases by local people in various countries. Recent work of its consumption has shown that OS had no genotoxic or organ toxic effects [5]. OS has been reported to possess therapeutic value for the treatment of several diseases [6] [7]. 1\% - 2\% of OS leaf powder in the diet caused a significant reduction of blood glucose in streptozotocin-induced DM rats [8] [9]. Aqueous extract of OS leaf extracts also delayed insulin resistance in normal rats fed with fructose diet [10], and also decreased blood glucose level in streptozotocin-induced DM rats [11] [12]. OS leaves possess not only antihyperglycemic activity but also organ protective effect against various stress conditions such as hyperlipidemia [13], inflammation [14] carcinogens [15], heavy metal [16] [17] and isoproterenal-induced myocardial necrosis [18]. It is known that the liver and kidney are the primary risk organs in diabetes. Therefore most researchers have focused on hepatic and renal protective activities of various medical plants in diabetes. However, diabetes impairs not only the liver and kidney but also the heart [19]. Diabetes has a high relevance with cardiovascular diseases including hypertension and ischemic heart disease [20]. Since our previous study showed that OS leaf powder in the diet reduced blood glucose and serum marker enzymes of liver and kidney function in streptozotocin-induced DM rats [9]. However, what kinds of chemical constituents in OS leaves responsible for its effects has not yet been undertaken. Moreover, no evidence to support its anti-oxidative activity to protect heart against diabetes is currently known. OS leaves have been reported to contain several chemical constituents such as phenolic compounds and fatty acids [6] [21] [22]. Moreover, aqueous extracts of OS leaves has been reported to express strong antioxidant activity both in vivo and in vitro studies [23] [24]. Therefore the present study was conducted to elucidate anti-hyperglycemic, anti-hyperlipidemic and anti-oxidative activities to protect various vital organs in DM rats treated with aqueous extracts of OS leaves.

\section{Materials and Methods}

\subsection{Extraction of Ocimum sanctum L. Leaves}

OS fresh leaves were obtained from the Institute of Thai Traditional Medicine, the Ministry of Public Health of Thailand. Fresh leaves of OS were washed in tap water and then cut into small pieces. The cut leaves were then cleaned and dried at room temperature. Dried leaves of OS were ground into fine powder and extracted by water. The aqueous extracts were then frozen and dried, and dark-brown powder was obtained. After the extraction process, the percent yield of OS extracts was $13.25 \mathrm{~g}$ from $100 \mathrm{~g}$ of dried OS leaf powder. The aqueous extracts were collected and stored at $4^{\circ} \mathrm{C}$ before determination of their phenolic content.

\subsection{Determination of Total Phenolic Content in Ocimum sanctum L. Leaf Extracts}

The total phenolic content of OS leaf extract was determined using the Folin-Ciocalteu method. $0.1 \mathrm{ml}$ of 10 
$\mathrm{mg} / \mathrm{ml}\left(\mathrm{w} / \mathrm{v}\right.$ ) of OS extract was added to $1 \mathrm{ml}$ of $7 \% \mathrm{Na}_{2} \mathrm{CO}_{3}$ solution and mixed thoroughly; $0.1 \mathrm{ml}$ of FolinCiocalteu reagent was then added to the mixture. Distilled water was added to reach $2.5 \mathrm{ml}$, then the mixture was allowed to stand for 90 min with intermittent shaking. The absorbance was measured at $750 \mathrm{~nm}$ in a Benchmark plus microplate spectrophotometer (Bio-Rad Laboratories (UK) Ltd). The total phenolic content was determined from the standard gallic acid calibration curve, and it was expressed as mg of gallic acid equivalent/g of dry weight of the OS extracts.

\subsection{Animal Preparation}

Male Wistar rats weighing between 200 - 250 g were purchased from the Animal Center, Salaya Campus, Mahidol University, Thailand. The rats were cared for in accordance with the principles and guidelines of the Institutional Animal Ethics Committee of Rangsit University, which is under The National Council of Thailand for Laboratory Animal Care. The rats were housed in a 12-hr light-dark cycle room with controlled temperature at $25^{\circ} \mathrm{C} \pm 2{ }^{\circ} \mathrm{C}$ and fed with standard rat food and tap water ad libitum. Type I DM was induced by intraperitoneal injection of streptozotocin (STZ) dissolved in citrate buffer $\mathrm{pH} 4.5$ at a dose of $65 \mathrm{mg} / \mathrm{kgbw}$. Five days after STZ injection fasting blood glucose was measured, and only those rats with blood glucose $\geq 200 \mathrm{mg} / \mathrm{dl}$ were included in the study.

\subsection{Experimental Design}

Three groups of seven rats each were established including.

Group 1: normal control rats;

Group 2: normal DM rats;

Group 3: DM rats treated with aqueous extract of OS leaves (AQOS).

From our previous study, a supplementation of $2 \%(\mathrm{w} / \mathrm{w})$ dried OS leaf powder in the rats'diet for three weeks showed anti-hyperglycemic effects in DM rats [9]. The average amount of dried OS leaf powder consumed by each rat was approximately $4.45 \mathrm{~g} / \mathrm{kgbw} /$ day. Therefore the daily dose of AQOS administered in this study was calculated based on these values, and was approximately $590 \mathrm{mg} / \mathrm{kgbw} / \mathrm{day}$. After diabetic induction, DM rats were fed with AQOS by intragastric intubation once a day for three weeks. Blood was collected from rat's tail to determine blood glucose weekly. Both body weight and food intake were also determined once a week.

\subsection{Determination of Serum Lipid Profile, Insulin and Biochemical Evaluation of Liver, Kidney and Cardiac Injury}

At the end of the study, the rats were fasted overnight and were anesthetized by intraperitoneal injection with zolitil (40 mg/kgbw) plus xylazine (3 mg/kgbw). Blood was collected from the abdominal vein to determine serum insulin and serum lipid profile including total cholesterol, triglyceride, low density lipoprotein cholesterol (LDL-C), and high density lipoprotein cholesterol (HDL-C). Liver function was evaluated by assessing serum alanine aminotransferase (ALT), aspartate aminotransferase (AST), and alkaline phosphatase (ALP) levels. Cardiac injury was also evaluated by measuring serum lactate dehydrogenase (LDH) and creatine kinase MB subunit (CK-MB) levels. Kidney function was evaluated by measuring serum creatinine and BUN (blood urea nitrogen).

\subsection{Determination of Lipid Peroxide and the Activity of Antioxidant Enzymes in the Liver, Kidney and Heart}

At the end of the study, the rats were fasted overnight and were anesthetized by zolitil ( $40 \mathrm{mg} / \mathrm{kgbw}$ ) plus xylazine (3 mg/kgbw). Then the jugular vein was cannulated to perfuse ice-cold normal saline to remove the red blood cells. When all organs looked pale, the liver, kidney and heart were isolated, cleaned and weighed. All organs were kept at $-80^{\circ} \mathrm{C}$ until further analysis was done as following.

\subsubsection{Determination of Tissue Lipid Peroxide Content}

All organs were homogenized with $0.1 \mathrm{M}$ phosphate buffer $\mathrm{pH}$ 7.4. Lipid peroxides in the liver, kidney and heart were assessed with thiobarbituric acid reactive substances (TBARS) as previously described [25]. TBARS 
was expressed in nmole of malondialdehyde (MDA)/mg protein using 1,1,3,3-tetraethoxy propane as standard. Tissue protein levels were determined by Lowry's method [26].

\subsubsection{Determination of the Activities of Tissue Antioxidant Enzymes}

Tissue antioxidant enzymes including glutathione peroxidase (GPx), catalase (CAT) and superoxide dismutase (SOD) were determined. Liver, kidney and cardiac tissue homogenates were prepared by homogenizing the tissues in a $0.1 \mathrm{M}$ phosphate buffer $\mathrm{pH}$ 7.4. The homogenate was then centrifuged at $3000 \mathrm{rpm}, 4^{\circ} \mathrm{C}$ for $10 \mathrm{~min}$. The supernatant was collected and centrifuged again at $7800 \mathrm{~g}, 4^{\circ} \mathrm{C}$ for $30 \mathrm{~min}$. The supernatant fraction was collected and further centrifuged at $136,000 \mathrm{~g}, 4^{\circ} \mathrm{C}$ for $60 \mathrm{~min}$. The final supernatant was then analyzed for estimation of GPx, CAT and SOD activities using the procedures described by Tapple [27], Luck [28], and Winterbourn et al. [29] respectively.

\subsection{Evaluation of Tissues Morphology}

The liver, kidney and heart were isolated, cleaned, dried, and then fixed in a buffer solution of $10 \%$ neutral buffered formalin. As for histopathological observations, longitudinal sections of the myocardial tissue were cut at the macroscopic lesions. As for the liver and kidney, sections were cut through the macroscopic lesions as well. The sections were further cut to $5 \mu \mathrm{m}$ thickness, and stained with haematoxylin and eosin (H\&E) [30].

\subsection{Biochemical Assay}

Blood glucose was determined using blood glucose strip (Medisense UK Ltd, Abbott Lab, UK). The total serum levels of total cholesterol, triglyceride and HDL-C were assayed by using an enzymatic kit (Gesellschaft Für Biochemica und Diagnostica GmbH, Germany). LDL-C was calculated by using the equation: LDL-C = [TC-(HDL-C)]-(triglyceride/5). The serum levels of AST, ALT, creatinine, BUN, LDH and CK-MB were measured by using an enzymatic kit (Randox Laboratories, UK). Serum insulin was assayed by RIA method (Diagnostic Product, Co., Ltd, LA, USA).

\subsection{Statistical Analysis}

All values were presented as means \pm SEM. The results were analyzed by ANOVA. Duncan multiple rank test was performed to determine statistical significance among groups by using SPSS software version 11.5. Significant difference was accepted at $P<0.05$.

\section{Results}

The total phenolic content in AQOS was $90.4 \pm 4.5 \mathrm{mg}$ gallic acid equivalent/g of dried OS leaf extract. Figure 1 shows percent of body weight gain and food intake of all groups. Body weight gain of untreated DM rats was significantly lowered than that of normal rats throughout three weeks. The decreased body weight gain was raised in DM rats treated with AQOS. Food intake was significantly increased in DM rats, and was slightly lowered at the third week in DM rats treated with AQOS. AQOS slightly but significantly reduced high blood glucose of DM rats throughout three weeks of treatment (Figure 2). Serum insulin level was significantly decreased in DM rats but it was significantly raised in DM rats treated with AQOS (Table 1). Total cholesterol, triglyceride and LDL-C were augmented without significant change of HDL-C in untreated DM rats (Table 1). The high serum lipid profile was markedly and significantly depressed after AQOS treatment. Serum levels of AST, ALT, ALP, LDH, CK-MB, creatinine and BUN in untreated DM rats were significantly higher than that of normal rats (Table 2). The high serum levels of AST, ALT, ALP, LDH and CK-MB were reversed in DM rats treated with AQOS. AQOS also significantly decreased the high serum levels of creatinine and BUN.

The high level of tissue lipid peroxide as presented by TBARS was significantly increased whereas GPx, CAT and SOD activities were significantly decreased in the liver tissue of untreated DM rats (Table 3). AQOS treatment decreased the high level of TBARS, and normalized GPx and CAT activities without significant effect on SOD activity in the liver tissue. Renal TBARS level was raised in untreated DM rats. In contrast, both GPX and SOD activities were significantly suppressed whereas no significant reduced of CAT activity was observed in renal tissue of untreated DM rats. AQOS treatment normalized the high level of TBARS whereas it raised GPx and CAT activities without significant effect on SOD activity in the renal tissue. For cardiac tissue of 

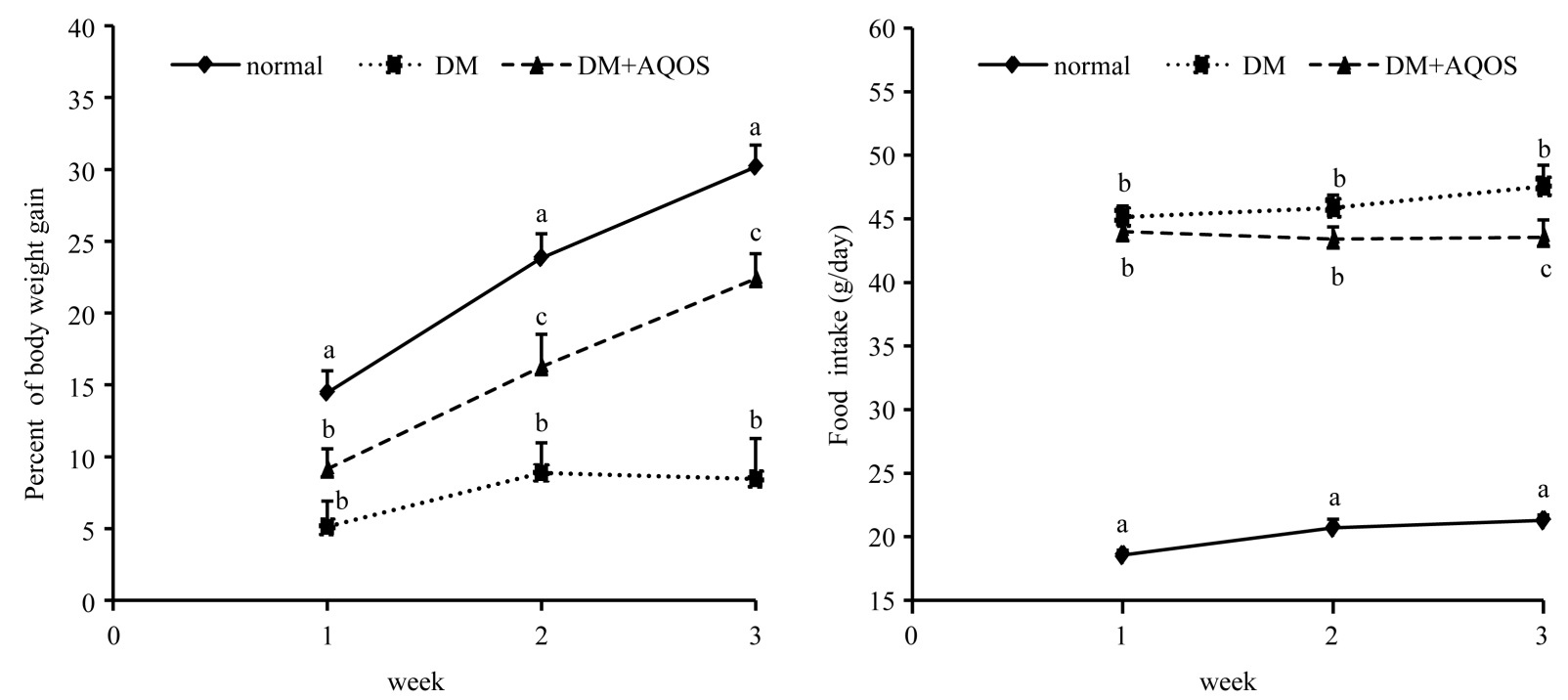

Figure 1. Percent of body weight gain and food intake of normal rats and DM rats treated with or without aqueous extracts of Ocimum sanctum L. leaves (AQOS) throughout three weeks. Data are presented as mean \pm SEM. Values with dif- ferent superscripts in the same week are significantly different at $P<0.05$.

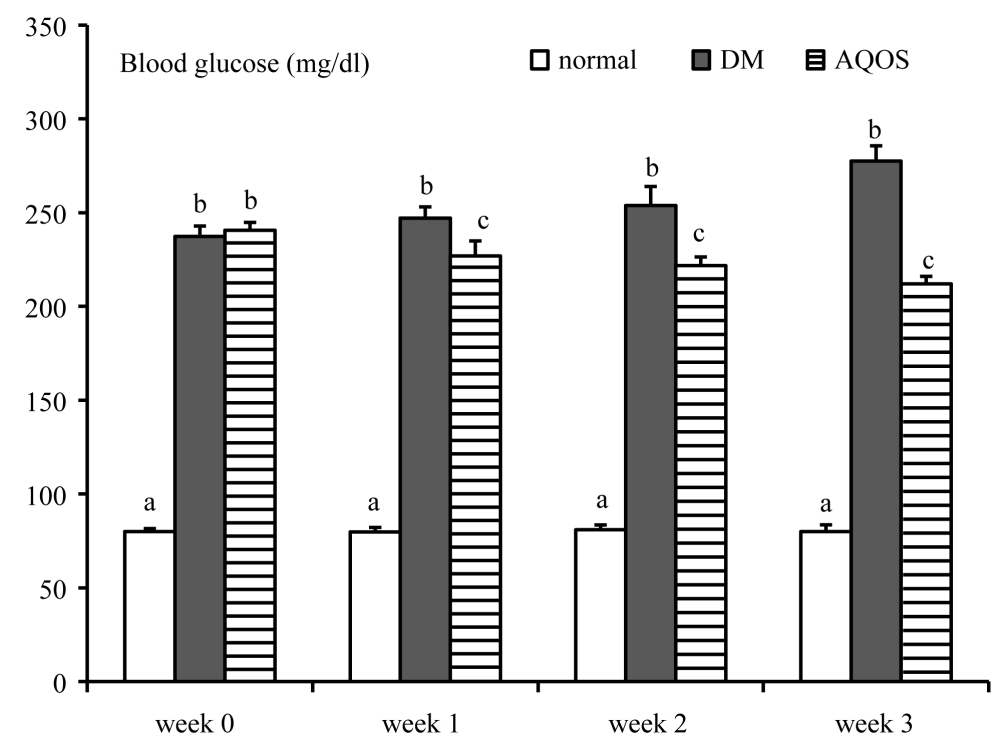

Figure 2. Changes of blood glucose of normal rats and DM rats treated with or without aqueous extracts of Ocimum sanctum L. leaves (AQOS) throughout three weeks. Data are presented as mean \pm SEM. Values with different superscripts in the same week are significantly different at $P<0.05$.

Table 1. Changes of serum insulin and serum lipid profile in normal rats and diabetic rats treated with or without aqueous extracts of Ocimum sanctum L. leaves (AQOS).

\begin{tabular}{cccccc}
\hline Group & $\begin{array}{c}\text { Serum insulin } \\
(\mu \mathrm{U} / \mathrm{ml})\end{array}$ & $\begin{array}{c}\text { Total cholesterol } \\
(\mathrm{mg} / \mathrm{dl})\end{array}$ & $\begin{array}{c}\text { Triglyceride } \\
(\mathrm{mg} / \mathrm{dl})\end{array}$ & $\begin{array}{c}\text { HDL-C } \\
(\mathrm{mg} / \mathrm{dl})\end{array}$ & $\begin{array}{c}\text { LDL-C } \\
(\mathrm{mg} / \mathrm{dl})\end{array}$ \\
\hline Normal & $6.39 \pm 0.3^{\mathrm{a}}$ & $55 \pm 3^{\mathrm{a}}$ & $61 \pm 6^{\mathrm{a}}$ & $20 \pm 1^{\mathrm{a}}$ & $22 \pm 2^{\mathrm{a}}$ \\
DM & $3.37 \pm 0.19^{\mathrm{b}}$ & $109 \pm 9^{\mathrm{b}}$ & $205 \pm 18^{\mathrm{b}}$ & $19 \pm 2^{\mathrm{a}}$ & $49 \pm 9^{\mathrm{b}}$ \\
DM + AQOS & $4.51 \pm 0.31^{\mathrm{c}}$ & $71 \pm 7^{\mathrm{a}}$ & $106 \pm 10^{\mathrm{c}}$ & $21 \pm 2^{\mathrm{a}}$ & $29 \pm 5^{\mathrm{a}}$ \\
\hline
\end{tabular}

Data are presented as mean \pm SEM. Values with different superscripts in the same column are significantly different at $P<0.05$. 
Table 2. Changes of alanine aminotransferase (ALT), aspartate aminotransferase (AST), alkaline phosphatase (ALP), lactate dehydrogenase (LDH), creatine kinase MB subunit (CK-MB), creatinine and BUN in serum of normal rats and diabetic rats treated with or without aqueous extracts of Ocimum sanctum L. leaves (AQOS).

\begin{tabular}{ccccccc}
\hline Group & AST (U/L) & ALT (U/L) & ALP (U/L) & LDH (U/L) & CK-MB (U/L) & Creatinine (mg/dl) \\
\hline Normal & $68 \pm 4^{\mathrm{a}}$ & $25 \pm 1^{\mathrm{a}}$ & $113 \pm 7^{\mathrm{a}}$ & $169 \pm 19^{\mathrm{a}}$ & $343 \pm 33^{\mathrm{a}}$ & $0.59 \pm 0.03^{\mathrm{a}}$ \\
DM & $155 \pm 34^{\mathrm{b}}$ & $77 \pm 14^{\mathrm{b}}$ & $439 \pm 61^{\mathrm{b}}$ & $390 \pm 56^{\mathrm{b}}$ & $495 \pm 36^{\mathrm{b}}$ & $0.86 \pm 0.08^{\mathrm{b}}$ \\
DM + AQOS & $67 \pm 7^{\mathrm{a}}$ & $37 \pm 4^{\mathrm{a}}$ & $217 \pm 29^{\mathrm{a}}$ & $253 \pm 28^{\mathrm{a}}$ & $379 \pm 31^{\mathrm{a}}$ & $0.51 \pm 0.04^{\mathrm{a}}$ \\
\hline
\end{tabular}

Data are presented as mean \pm SEM. Values with different superscripts in the same column are significantly different at $P<0.05$.

Table 3. Effect of aqueous extracts of Ocimum sanctum L. leaves (AQOS) on lipid peroxide and antioxidant enzymes activity in hepatic, kidney and cardiac tissues. (TBARS, thiobarbituric acid reactive substances (nmole MDA/mg protein); GPx, glutathione peroxidase ( $\mu$ mole/min/mg protein); CAT, catalase, $(\mu \mathrm{mole} / \mathrm{min} / \mathrm{mg}$ protein); SOD, superoxide dismutase (units/mg protein).

\begin{tabular}{lcccc}
\multicolumn{1}{c}{ Group } & TBARS & GPx & CAT & SOD \\
\hline Liver & & & \\
Normal & $0.97 \pm 0.04^{\mathrm{a}}$ & $1.03 \pm 0.06^{\mathrm{a}}$ & $265 \pm 26^{\mathrm{a}}$ & $125 \pm 17^{\mathrm{a}}$ \\
DM & $1.30 \pm 0.05^{\mathrm{b}}$ & $0.64 \pm 0.07^{\mathrm{b}}$ & $127 \pm 15^{\mathrm{b}}$ & $48.6 \pm 7.6^{\mathrm{b}}$ \\
DM + AQOS & $1.10 \pm 0.01^{\mathrm{c}}$ & $0.98 \pm 0.03^{\mathrm{a}}$ & $227 \pm 22^{\mathrm{a}}$ & $54.2 \pm 7.5^{\mathrm{b}}$ \\
Kidneys & & & \\
Normal & $0.96 \pm 0.02^{\mathrm{a}}$ & $1.03 \pm 0.02^{\mathrm{a}}$ & $4.87 \pm 0.42^{\mathrm{a}}$ & $58.8 \pm 4.6^{\mathrm{a}}$ \\
DM & $1.16 \pm 0.03^{\mathrm{b}}$ & $0.82 \pm 0.07^{\mathrm{b}}$ & $4.60 \pm 0.45^{\mathrm{a}}$ & $29.3 \pm 4.7^{\mathrm{b}}$ \\
DM + AQOS & $0.92 \pm 0.04^{\mathrm{a}}$ & $1.11 \pm 0.04^{\mathrm{a}}$ & $6.65 \pm 0.70^{\mathrm{c}}$ & $27.4 \pm 1.5^{\mathrm{b}}$ \\
Heart & & & & \\
Normal & $0.70 \pm 0.02^{\mathrm{a}}$ & $0.28 \pm 0.02^{\mathrm{a}}$ & $8.71 \pm 0.9^{\mathrm{a}}$ & $36.9 \pm 6.5^{\mathrm{a}}$ \\
DM & $0.96 \pm 0.03^{\mathrm{b}}$ & $0.26 \pm 0.01^{\mathrm{a}}$ & $21.2 \pm 3.6^{\mathrm{b}}$ & $37.9 \pm 4.7^{\mathrm{a}}$ \\
DM + AQOS & $0.85 \pm 0.02^{\mathrm{c}}$ & $0.30 \pm 0.02^{\mathrm{a}}$ & $20.2 \pm 1.4^{\mathrm{b}}$ & $60.5 \pm 5.6^{\mathrm{c}}$ \\
\hline
\end{tabular}

Data are presented as mean \pm SEM. Values with different superscripts in the same column are significantly different at $P<0.05$.

untreated DM rats, both TBARS and CAT activities were significantly increased without significant changes of both GPx and SOD activities. AQOS treatment attenuated the high level of TBARS and significantly raised SOD activity without changes of both GPx and CAT activities. Tissue morphological appearances in normal rats and DM rats treated with or without AQOS were shown in Figures 3-5. From histopathological analysis, the normal hepatocytes had centrally round nuclei and flat endothelial cells around the central vein and sinusoid (Figure 3(A)). For DM rats, there were hepatocyte degenerations with cytoplasmic vacuolization (Figure 3(B)). Some of hepatocyte around central vein demonstrated hepatic cell degeneration and necrosis (loss of nucleus). However, the endothelial lining of the central vein exhibited less cell injury and fewer fat vacuoles in hepatocytes. Nearly general normal appearance of hepatocytes with less fat vacuole was shown in DM rats treated with AQOS (Figure 3(C)). No remarkable lesions were shown in renal tissue of normal control rats (Figure 4(A)). Renal tissues of DM rats showed mild to moderate mesangial cells proliferation and cellular matrix expansion. Multifocal degenerations and necrosis of distal convoluted tubular epithelial cells were also observed (Figure 4(B)). AQOS treatment improved the renal tissue with less congestion and less proliferation of mesangial cells (Figure 4(C)). Also, renal tubular cells were quietly reversed to normal. Myocardiocytes of normal rats had oval-elongated nuclei centrally and a homogeneous cytoplasm (Figure 5(A)). The DM rats exhibited a moderate dilation and thinning of the right ventricle wall with mild cardiac hypertrophy of the left ventricle. Multifocal 

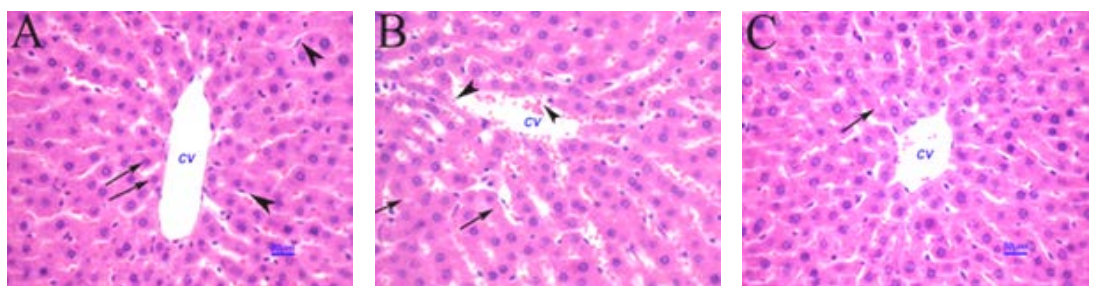

Figure 3. Histopathological appearance of hepatic tissues of normal control rats (A), DM rats (B), and DM rats treated with AQOS (C) (H\&Ex400). Hepatocytes of the normal control rat exhibited centrally round nuclei (arrow) that are arranged in regular hepatic cords from central vein (CV). Flatted endothelial cells were observed at the wall of central vein and luminal surface of hepatic sinusoid (arrowheads). Liver tissue of DM rats demonstrated hepatocyte degenerations with cytoplasmic vacuolization (arrows). Some of hepatocytes depositing around the central vein also exhibited cellular necrosis or degenerations (arrowheads). Minimal injury of endothelial cells lining the central vein was observed. Hepatic tissue of the DM rats treated with AQOS revealed general normal histology with less fat vacuoles (arrow) (C).
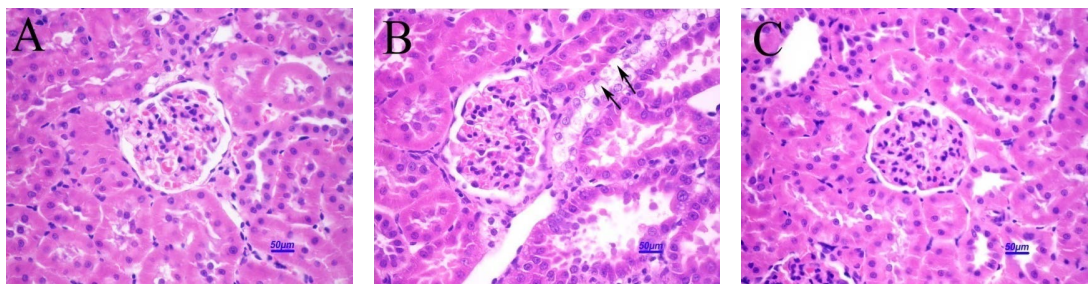

Figure 4. Photomicrographs exhibiting histopathological appearances of kidney tissues of normal control rats (A), DM rats (B), and DM rats treated with AQOS (C) (H\&Ex400). Non-remarkable lesions were shown in kidney tissue of the normal control rats. For DM rat, mild to moderate mesangial cell proliferation and cellular matrix expansion was noticeable. Focal degenerations and cellular necrosis of epithelial cells of distal convoluted tubules were remarkable (arrows). General appearance was quite normal with mild proliferation of mesangial cell without cellular matrix expansion in DM rats treated with AQOS.
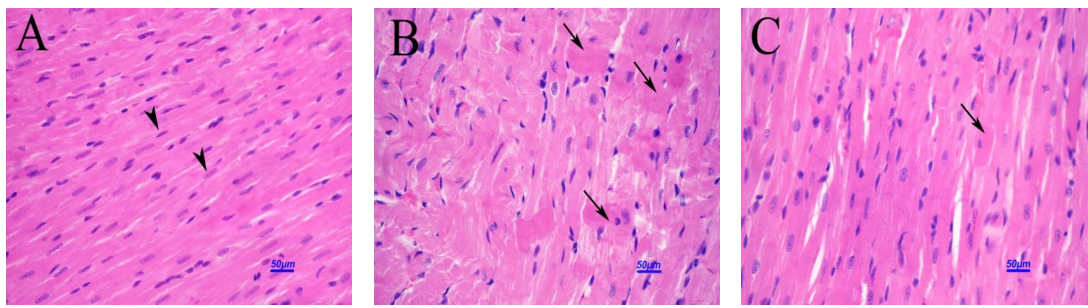

Figure 5. Histopathological appearance of the cardiac tissues of normal control rats (A), DM rats (B), and DM treated with AQOS (C) (H\&Ex400). Cardiac tissue of control rat had non remarkable lesions. Normal myocardial cell morphology with oval-elongate were observed (arrowheads). For DM rats, multifocal myocardium degenerations and cellular necroses were noticeable (arrows). General improvement of myocardial cell morphology with less degenerations and cellular necrosis (arrow) (C).

vacuolar degeneration and necrosis were seen in the myocardiocyte of DM rats (Figure 5(B)). After AQOS treatment, the general appearance of myocardiocytes was markedly improved with less focal vacuolar degeneration and necrosis (Figure 5(C)).

\section{Discussion}

Similar to the other serious diseases such as cancer, DM is poised to become one of the largest global health 
problems in the $21^{\text {st }}$ century because of its influences on multiple organ systems leading to serious complications. Owing to undesirable side effects, cost and safety on long-term use of synthetic hypoglycemic drugs, searching for new medicine to fulfill the requirement for life-long treatment is necessary. During the past decade, it is widely accepted that medicines of herbal origin play an essential role in treating diverse diseases since they are enriched of bioactive photochemical ingredients that might offer effective safe, and cheap therapy. Ocimum sanctum L. (OS), commonly used as a cooking vegetable, has shown its potency as a therapeutic herb and safe for long term consumption as mentioned earlier. The present study shows that AQOS decreased the high blood glucose and serum lipid profile in DM rats (Figure 2 and Table 1). Its lipid-lowering effect might be a beneficial property in preventing cardiovascular disease in diabetes. AQOS has been reported to induce glucose-stimulated insulin release in isolated pancreatic $\beta$-cells [31]. Therefore, the anti-hyperglycemic and lipid-lowering activities of AQOS should be due to its effect to improve pancreatic $\beta$-cells function. This is supported by an increased serum insulin level in DM rats treated with AQOS.

Increased oxidative stress and lower antioxidant enzyme activities have been known to be the significant causes of cellular injury in variety of stress conditions. An elevation of blood glucose induces oxidative stress, resulting in an increased production of oxygenated free radicals. This leads to intracellular structure modification, and finally affects for proper cell functioning [32] [33]. This process is the initiating event leading to pathogenesis and development of diabetic complications. To prevent damage by free radicals, cells have to develop antioxidant defense system. As mentioned earlier, diabetes impairs not only the liver and kidney but also the heart. Numerous studies have revealed that OS leaves had organ protective activities against various stress conditions including hyperlipidemia, heavy metal exposure and cancer [13] [15] [16]. Our results show that diabetes impaired liver, kidney and heart functions as expressed by an augmentation of serum levels of AST, ALT, ALP, creatinine, BUN, LDH and CK-MB (Table 2). TBARS levels were significantly increased whereas the activities of antioxidant enzymes were significantly decreased in the liver and renal tissues of untreated DM rats (Table 3). AQOS treatment suppressed high serum levels of AST, ALT, ALP, creatinine and BUN. It also suppressed the high level of TBARS, and raised GPx and CAT activities in both the liver and renal tissues. These reflect that three weeks of diabetic induction induces oxidative stress to impair the liver and renal tissues, and AQOS had a free radical scavenging activity which provides organs protection against diabetes. Supporting for this interpretation is that nearly general normal appearances of the liver and renal tissue were shown by histopathological study (Figure 3, Figure 4).

Interesting to note that TBARS level was raised without significant changes of both GPx and SOD whereas CAT was extremely increased in cardiac tissue of untreated DM rats. It has been reported that during an elevated oxidative stress, cells try to protect themselves by increased activities of various antioxidant enzymes. Therefore the augmentation of cardiac CAT activity might be compensatory response against oxidative stress from diabetes [34] [35]. Though AQOS treatment had no effect to promote GPx and CAT activities, it markedly enhanced SOD activity to alleviate the high level of TBARS in cardiac tissues, which then finally improved cardiac injury from diabetes as shown by histopathological examination (Figure 5).

Of particular interest is that AQOS raised renal CAT activity and cardiac SOD activity to the level that were higher than that of normal level. The real mechanism why the activities of these antioxidant enzymes were markedly higher than that of normal rats cannot yet be explained by the present study. It is known that SOD neutralizes superoxide anions to hydrogen peroxide which is broken down by CAT and GPx, and then prevents further generation of free radicals. As shown in Table 3, the elevation of cardiac CAT activity in untreated DM rats might not have a powerful capacity to protect heart against oxidative stress from diabetes since high levels of cardiac TBARS was remained. This means that a lot of free radicals were produced in cardiac tissue of DM rats. AQOS markedly enhance cardiac SOD activity in order to catalyze excess free radicals produced in cardiac tissue of DM rats. Similarly, an elevation of renal GPx activity alone in DM rats treated with AQOS might not be able to get rid of excess free radicals, thus an extremely powerful capacity of renal CAT should be necessary. It can be clearly shown from the present study that AQOS may be of therapeutic importance, not only as an antihyperglycemic and lipid-lowering agent but also as a cytoprotective agent to protect the liver, heart and renal injury from diabetes.

The present results show that AQOS contained a significant amount of phenolic compounds. Several lines of evidences showed that plants with phenolic compounds had anti-hyperglycemic, anti-lipidemic and anti-oxidative activities to protect risk organs from diabetes [36] [37]. This reflects that phenolic compounds in AQOS might be responsible for those actions in DM rats. However, it has not yet been known what kinds of phenolic 
compounds in AQOS that were responsible for those actions, hence, they should be further identified. OS leaves are not only safe to consume but they are also easily to be cultivated and routinely used as cooking vegetable in various countries. Our study shows that AQOS had several outstanding effects in DM rats. Therefore AQOS may be developed to be drug of choice to treat diabetic patient. This should be further studied.

\section{Conclusion}

It can be concluded that treatment of AQOS for three weeks significantly lowered blood glucose and serum lipid profile whereas it raised serum insulin level in DM rats. AQOS had a free radical scavenging activity which provided organ protection from diabetes by suppression of high TBARS levels and enhancement of the activities of antioxidant enzymes in the liver, kidney and cardiac tissues. Histopathological study shows that AQOS protected the liver, kidney and myocardial tissues from diabetes. The phenolic compounds contained in AQOS might be responsible for the anti-hyperglycemic, anti-hyperlipidemic and protective activities against diabetes.

\section{Acknowledgements}

We would like to thank the Thailand Research Fund for research grant to support this project.

\section{References}

[1] Gezginci-Oktayoglu, S., Basaraner, H., Yanardag, R. and Bolkent, S. (2009) The Effects of Combined Treatment of Antioxidants on the Liver Injury in STZ Diabetic Rats. Digestive Diseases and Sciences, 54, 538-546. http://dx.doi.org/10.1007/s10620-008-0381-0

[2] American Diabetes Association (2010) Diagnosis and Classification of Diabetes Mellitus. Diabetes Care, 33, S62-S69. http://dx.doi.org/10.2337/dc10-S062

[3] Wild, S., Roglic, G., Green, A., Sicree, R. and King, H. (2004) Global Prevalence of Diabetes: Estimates for the Year 2000 and Projections for 2030. Diabetes Care, 27, 1047-1053. http://dx.doi.org/10.2337/diacare.27.5.1047

[4] Emilien, G., Maloteaux, J.M. and Ponchon, M. (1999) Pharmacological Management of Diabetes: Recent Progress and Future Perspective in Daily Drug Treatment. Pharmacology and Therapeutics, 81, 37-51. http://dx.doi.org/10.1016/S0163-7258(98)00034-5

[5] Chandrasekaran, C.V., Srikanth, H.S., Anand, M.S., Allan, J.J., Viji, M.M. and Amit, A. (2013) Evaluation of the Mutagenic Potential and Acute Oral Toxicity of Standardized Extract of Ocimum sanctum (OciBest ${ }^{\mathrm{TM}}$ ). Human and Experimental Toxicology, 32, 992-1004. http://dx.doi.org/10.1177/0960327112472992

[6] Mahajan, N., Rawal, S., Verma, M., Poddar, M. and Alok, S. (2013) A Phytopharmacological Overview on Ocimum Species with Special Emphasis on Ocimum sanctum. Biomedicine and Preventive Nutrition, 3, 185-192. http://dx.doi.org/10.1016/j.bionut.2012.08.002

[7] Pattanayak, P., Behera, P., Das, D. and Panda, S.K. (2010) Ocimum sanctum Linn. A Reservoir Plant for Therapeutic Applications: An Overview. Pharmacognosy Review, 4, 95-105. http://dx.doi.org/10.4103/0973-7847.65323

[8] Sethi, J., Sood, S., Seth, S. and Talwar, A. (2004) Evaluation of Hypoglycemic and Antioxidant Effect of Ocimum sanctum. Indian Journal of Clinical Biochemistry, 19, 152-155. http://dx.doi.org/10.1007/BF02894276

[9] Suanarunsawat, T. and Songsak, T. (2005) Anti-Hyperglycemic and Anti-Hyperlipidemic Effect of Dietary Supplement of White Ocimum sanctum L. before and after STZ-Induced Diabetes Mellitus. International Journal of Diabetes and Metabolism, 13, 18-23.

[10] Reddy, S.S., Karuna, R., Baskar, R. and Saralakumari, D. (2008) Prevention of Insulin Resistance by Ingesting Aqueous Extract of Ocimum sanctum to Fructose-Fed Rats. Hormone and Metabolic Research, 40, 44-49. http://dx.doi.org/10.1055/s-2007-993218

[11] Narendhirakannan, R.T., Subramanian, S. and Kandaswamy, M. (2006) Biochemical Evaluation of Antidiabetogenic Properties of Some Commonly Used Indian Plants on Streptozotocin-Induced Diabetes in Experimental Rats. Clinical and Experimental Pharmacology and Physiology, 33, 1150-1157. http://dx.doi.org/10.1111/j.1440-1681.2006.04507.x

[12] Patil, R.N., Patil, R.Y., Ahirwar, B. and Ahirwar, D. (2011) Evaluation of Antidiabetic and Related Actions of Some Indian Medicinal Plants in Diabetic Rats. Asian Pacific Journal of Tropical Medicine, 4, 20-23. http://dx.doi.org/10.1016/S1995-7645(11)60025-4

[13] Suanarunsawat, T., Ayutthaya, W.D., Songsak, T., Thirawarapan, S. and Poungshompoo, S. (2011) Lipid-Lowering and Antioxidative Activities of Aqueous Extracts of Ocimum sanctum L. Leaves in Rats Fed with a High-Cholesterol Diet. Oxidative Medicine and Cellular Longevity, 2011, Article ID 962025.

http://dx.doi.org/10.1155/2011/962025 
[14] Shetty, S., Udupa, S. and Udupa, L. (2008) Evaluation of Antioxidant and Wound Healing Effects of Alcoholic and Aqueous Extract of Ocimum sanctum Linn in Rats. Evidence-Based Complementary and Alternative Medicine, 5, 95101. http://dx.doi.org/10.1093/ecam/nem004

[15] Manikandan, P., Murugan, R.S., Abbas, H., Abraham, S.K. and Nagini, S. (2007) Ocimum sanctum Linn. (Holy Basil) Ethanolic Leaf Extract Protects against 7,12-Dimethylbenz(a)Anthracene-Induced Genotoxicity, Oxidative Stress, and Imbalance in Xenobiotic-Metabolizing Enzymes. Journal of Medicinal Food, 10, 495-502. http://dx.doi.org/10.1089/jmf.2006.125

[16] Sharmila, B.G., Kumar, G. and Murugesan, A.G. (2009) Effects of Leaves Extract of Ocimum sanctum L. on Arsenic-Induced Toxicity in Wistar Albino Rats. Food and Chemical Toxicology, 47, 490-495. http://dx.doi.org/10.1016/j.fct.2008.12.004

[17] Ramesh, B. and Satakopan, V.N. (2010) Antioxidant Activities of Hydroalcoholic Extract of Ocimum sanctum against Cadmium Induced Toxicity in Rats. Indian Journal of Clinical Biochemistry, 25, 307-310. http://dx.doi.org/10.1007/s12291-010-0039-5

[18] Sood, S., Narang, D., Dinda, A.K. and Maulik, S.K. (2005) Chronic Oral Administration of Ocimum sanctum Linn Augments Cardiac Endogenous Antioxidants and Prevents Isoproterenal-Induced Myocardial Necrosis in Rats. Journal of Pharmacy and Pharmacology, 57, 127-133. http://dx.doi.org/10.1211/0022357055146

[19] Li, C.J., Lv, L., Li, H. and Yu, D.M. (2012) Cardiac Fibrosis and Dysfunction in Experimental Diabetic Cardiomyopathy Are Ameliorated by Alpha-Lipoic Acid. Cardiovascular Diabetology, 11, 73. http://dx.doi.org/10.1186/1475-2840-11-73

[20] Mercer, B.N., Morais, S., Cubbon, R.M. and Kearney, M.T. (2012) Diabetes Mellitus and the Heart. International Journal of Clinical Practice, 66, 640-647. http://dx.doi.org/10.1111/j.1742-1241.2012.02924.x

[21] Anandjiwala, S., Kalola, J. and Rajani, M. (2006) Quantification of Eugenol, Luteolin, Ursolic Acid, and Oleanolic Acid in Black (Krishna Tulasi) and Green (Sri Tulasi) Varieties of Ocimum sanctum Linn. Using High-Performance Thin-Layer Chromatography. Journal of AOAC International, 89, 1467-1474.

[22] Suanarunsawat, T., Boonnak, T., Ayutthaya, W.D. and Thirawarapan, T. (2010) Anti-Hyperlipidemic and Cardioprotective Effects of Ocimum sanctum L. Fixed Oil in Rats Fed a High Fat Diet. Journal of Basic and Clinical Physiology and Pharmacology, 21, 387-400. http://dx.doi.org/10.1515/JBCPP.2010.21.4.387

[23] Gülçin, I., Elmastaş, M., and Aboul-Enein, H.Y. (2007) Determination of Antioxidant and Radical Scavenging Activity of Basil (Ocimum basilicum L. Family Lamiaceae) Assayed by Different Methodologies. Phytotherapy Research, 21, 354-361. http://dx.doi.org/10.1002/ptr.2069

[24] Geetha, R.K. and Vasudevan, D.M. (2004) Inhibition of Lipid Peroxidation by Botanical Extracts of Ocimum sanctum: in vivo and in vitro Studies. Life Sciences, 76, 21-28. http://dx.doi.org/10.1016/j.lfs.2004.05.036

[25] Ohkawa, H., Ohishi, N. and Yagi, K. (1979) Assay for Lipid Peroxides in Animal Tissues by Thiobarbituric Acid Reaction. Analytical Biochemistry, 95, 351-358. http://dx.doi.org/10.1016/0003-2697(79)90738-3

[26] Lowry, O.H., Rosebrough, N.J., Farr, A.L. and Randall, R.J. (1951) Protein Measurement with the Folin Phenol Reagent. Journal of Biological Chemistry, 193,265-275.

[27] Tapple, A.L. (1978) Glutathione Peroxidase and Hydroperoxidase Methods. In: Sidney, F. and Lester, P., Eds., Methods in Enzymology, Academic Press, New York, 506-513.

[28] Luck, H. (1965) Catalase. In: Bergmeyer, H.U., Ed., Method of Enzymatic Analysis, Academic Press, New York and London, 885-894. http://dx.doi.org/10.1016/B978-0-12-395630-9.50158-4

[29] Winterbourn, C.C., Hawkins, R.E., Brian, M. and Carrell, R.W. (1975) The Estimation of Red Cell Superoxide Dismutase Activity. The Journal of Laboratory and Clinical Medicine, 85, 337-341.

[30] Humanson, G.L. (1979) Part I Basic Procedure. In: Freeman, W.H., Ed., Animal Tissue Technique, 4th Edition, W. H. Freeman and Company, San Francisco, 1-129.

[31] Hannan, J.M., Marenah, L., Ali, L., Rokeya, B., Flatt, P.R. and Abdel-Wahab, Y.H. (2006) Ocimum sanctum Leaf Extracts Stimulate Insulin Secretion from Perfused Pancreas, Isolated Islets and Clonal Pancreatic Beta-Cells. Journal of Endocrinology, 89, 127-136. http://dx.doi.org/10.1677/joe.1.06615

[32] Wiernsperger, N.F. (2003) Oxidative Stress as a Therapeutic Target in Diabetes: Revisiting the Controversy. Diabetes and Metabolism, 29, 579-585. http://dx.doi.org/10.1016/S1262-3636(07)70072-1

[33] King, G.L. and Loeken, M.R. (2004) Hyperglycemia-Induced Oxidative Stress in Diabetic Complications. Histochemistry and Cell Biology, 122, 333-338. http://dx.doi.org/10.1007/s00418-004-0678-9

[34] Kumar, S., Prasad, S. and Sitasawad, S.L. (2013) Multiple Antioxidants Improve Cardiac Complications and Inhibit Cardiac Cell Death in Streptozotocin-Induced Diabetic Rats. PLoS ONE, 8, e67009. http://dx.doi.org/10.1371/journal.pone.0067009 
[35] Zobali, F., Avci, A., Canbolat, O. and Karasu, C. (2002) Effects of Vitamin A and Insulin on the Anti-Oxidative State of Diabetic Rat Heart: A Comparison Study with Combination Treatment. Cell Biochemistry and Function, 20, 75-80. http://dx.doi.org/10.1002/cbf.957

[36] Fenercioglu, A.K., Saler, T., Genc, E., Sabuncu, H. and Altuntas, Y. (2010) The Effects of Polyphenol-Containing Antioxidants on Oxidative Stress and Lipid Peroxidation in Type 2 Diabetes Mellitus without Complications. Journal of Endocrinological Investigation, 33, 118-124.

[37] Stephen, I.S., Sunil, C., Duraipandiyan, V. and Ignacimuthu, S. (2012) Antidiabetic and Antioxidant Activities of Toddalia asiatica (L.) Lam. Leaves in Streptozotocin Induced Diabetic Rats. Journal of Ethnopharmacology, 143, 515-523. http://dx.doi.org/10.1016/j.jep.2012.07.006. 